\title{
Study on the equity of medical services utilization for elderly enrolled in different basic social medical insurance systems in an underdeveloped city of Southwest China
}

\author{
Rao Chen, Ning-xiu Li and Xiang Liu*
}

\begin{abstract}
Background: The equity of medical services utilization for elderly individuals enrolled in different basic social medical insurance systems holds significant meaning for social harmony against a background of demographic aging and a growing wealth gap in China. This study is to explore the equity of the three medical insurance systems in southwest China with the aim of providing recommendations for relevant policy.

Methods: A total of 9600 elderly people insured through basic social medical insurance were selected and interviewed with a questionnaire. This study used a binary logistic regression model to investigate the effect of household income for medical services utilization and adopted a concentration index to measure the inequity of medical services utilization among elderly participants enrolled in different medical insurance categories.

Results: Outpatient services utilization was almost identical in the different insurance systems (78.5\%, $77.7 \%$ and $78.6 \%)$. There were no statistically significant differences according to income level in the Urban Employee Basic Medical Insurance (UEBMI) and Urban Resident Basic Medical Insurance (URBMI) programs, but in the New Cooperative Medical Scheme (NCMS), higher-income groups tended to utilize more services. The corresponding concentration index (Cl) values were $0.0162,0.0173$ and 0.0179 respectively. The NCMS showed a lower hospitalization rate than UEBMI and URBMI (17.7\% vs $24.2 \%$ and $24.9 \%)$. The higher income group utilized hospitalization more, regardless of the insurance system. The corresponding $\mathrm{Cl}$ values were $0.0817,0.0605$ and 0.0319 respectively.

Conclusion: The equity of medical services utilization for elderly exist in all three health insurance systems, in particular, the inequities in utilization of hospitalization were more severe than outpatient services. UEBMI and URBMI were better than NCMS in the equity of outpatient services. Although NCMS was more equitable than URBMI and UEBMI in terms of hospitalization, this was based on "overall low utilization of hospitalization regardless of income levels" in NCMS compared with URBMI and UEBMI. The disparities of the three basic social medical insurance systems should be eliminated. For low-income residents, specific insurance policies including reducing deductible, covering more medical service and increasing reimbursement ratio could be considered.
\end{abstract}

Keywords: Utilization of medical services, Basic social medical insurance, Health equity, Elderly

\footnotetext{
* Correspondence: new9812@126.com

West China School of Public Health, Sichuan University, No. 17 Section 3,

Renmin South Road, Chengdu 610041, Sichuan, China
}

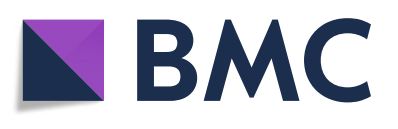

(c) The Author(s). 2018 Open Access This article is distributed under the terms of the Creative Commons Attribution 4.0 International License (http://creativecommons.org/licenses/by/4.0/), which permits unrestricted use, distribution, and reproduction in any medium, provided you give appropriate credit to the original author(s) and the source, provide a link to the Creative Commons license, and indicate if changes were made. The Creative Commons Public Domain Dedication waiver (http://creativecommons.org/publicdomain/zero/1.0/) applies to the data made available in this article, unless otherwise stated. 


\section{Background}

Over the last few decades, as China's economic reform has sparked unprecedented economic growth, social resources have grown as well [1]. At the same time, concern for the equitable distribution of social benefits has also grown. As one of the most important social benefits, health resources have attracted considerable public attention. However, in recent years, as China's health inequities have been increasing, public dissatisfaction has been growing $[2,3]$. Health equity is the absence of systematic disparities in health between groups with different levels of underlying social advantage/disadvantage [4]. While health equity includes several important elements [5], medical services utilization, as one of these elements, was the focus of our study. The equity of medical services utilization does not mean that people with different incomes have the same rate of utilization. Instead, real equity means that utilization is not influenced by circumstances such as the ability to pay, but that people who need the services can utilize the services without financial burden [6].

Empirical evidence indicates that there is a strong correlation between income and the utilization of medical services [7, 8]. Furthermore, there is a growing income gap between rich and poor in China [9]. As a result, economic inequity is bound to cause inequity in medical services utilization [8]. To reduce inequity, the Chinese government has established a graded social medical insurance system to serves as the major source of healthcare financing and payment, which consists of three types of medical insurance. The major distinguishing features of these three schemes are that the availability of a specific medical insurance schemes depends on one's employment status and/or residency status (urban vs. rural) [10]:Urban Employee Basic Medical Insurance (UEBMI) for the urban employed, Urban Resident Basic Medical Insurance (URBMI) for the urban unemployed resident, and the New Cooperative Medical Scheme (NCMS) for the rural population [11]. These three medical insurance schemes covered approximately 1.2 billion people ( $90 \%$ of the Chinese population), but each scheme operates independently, and contributions come from a variety of sources, including the central government, local governments, employers, employees, and residents [12]. For UEBMI, both employers and employees are required to contribute approximately 6 and $2 \%$, respectively, of employees' annual wages to the scheme. The source of the other two schemes are from individual premium contributions and subsides from central and local government. The government subsides in 2011 were 200 Yuan, individual premium contributions were varied by locations. So, the per-capita fund and annual maximum reimbursement cap were different in different schemes. In regard to the service package, compared with the comprehensive coverage of UEBMI, the other two schemes' coverage focused on inpatient and catastrophic illness for outpatient services, while denying coverage for some basic outpatient services [10]. Table 1 contains basic information about the three social health insurance schemes in China [10, 13].

Many studies have concluded that the medical insurance system plays a vital role in the equity of medical services utilization [13-16]. Additionally, they have shown that great disparities exist between people insured by different medical insurance schemes with regard to access to medical services. These disparities are part of the nature of the three systems in China, which base the level and type of insurance on individuals' social attributes and function independently of each other, differing, for example, in aspects related to financing, reimbursement, and expansion as above [11]. Previous studies have attached great importance to comparing the three systems. For example, Meng et al. [13] and Lin et al. [17] noted that rural populations have more

Table 1 Basic information about the three medical insurance schemes in China

\begin{tabular}{|c|c|c|c|}
\hline & UEBMI & URBMI & NCMS \\
\hline Inception year & 1998 & 2007 & 2003 \\
\hline Eligible population & Urban, employed & Urban, non-employed & All rural population \\
\hline $\begin{array}{l}\text { Number of people insured } \\
\text { (2013) }\end{array}$ & 265 million & 271 million & 805 million \\
\hline Source of founding (2011) & $\begin{array}{l}\text { Contributory ( } 8 \% \text { of annual wage, } 6 \% \\
\text { from employers, and } 2 \% \text { from } \\
\text { employees) }\end{array}$ & $\begin{array}{l}\text { Government subsidy ( } 200 \text { Yuan) and } \\
\text { individual premium (varied by } \\
\text { locations) }\end{array}$ & $\begin{array}{l}\text { Government subsidy ( } 200 \text { Yuan) and } \\
\text { individual premium (varied by } \\
\text { locations) }\end{array}$ \\
\hline Per-capita fund (2013) & 2688.9 Yuan & 419.1 Yuan & 387.5 Yuan \\
\hline $\begin{array}{l}\text { Annual maximum } \\
\text { reimbursement cap(2011) }\end{array}$ & $\begin{array}{l}6 \text { times of disposable personal income } \\
\text { (at least } 50,000 \text { Yuan) }\end{array}$ & $\begin{array}{l}6 \text { times of disposable personal } \\
\text { income (at least 50,000 Yuan) }\end{array}$ & at least 50,000 Yuan \\
\hline $\begin{array}{l}\text { Inpatient and outpatient } \\
\text { services for catastrophic } \\
\text { illness }\end{array}$ & Yes & Yes & Yes \\
\hline General outpatient services & Comprehensive & Limited and varied by locations & Limited and varied by locations \\
\hline
\end{tabular}


restricted access to medical services and show a larger financial burden than urban cohorts, mainly due to low funds for the NCMS. Furthermore, UEBMI has more comprehensive services coverage and financial protections than URBMI and the NCMS [18].

Recent years, populations are growing older in nearly all the countries of the world especially in China [19]. Ageing process could reflect some extent of socioeconomic development, for instance the health problems of the aging of population have been a great challenge to social development $[20,21]$. Many studies have indicated that the elderly as a group are the greatest adult users of the health care system due to poor health [22-24]. A number of scholars have begun to explore the health inequity among the elderly. For instance, $\mathrm{Lu}$ et al. [25] found that health equity was at a general level and that inequity in hospitalization was significant among the elderly in Fujian province. However, to date, there has been little research on the equity of medical services utilization among the elderly categorized according to the three categories of medical insurance in China.

This study was conducted in southwestern China, in Sichuan province, which is one of China's relatively undeveloped provinces. The aging problem is serious in Sichuan province, where the proportion of people aged over 60 was 20.02\% in 2016 [26]. With this background, we conducted this study to compare the utilization of outpatient and hospitalization services among elderly individuals enrolled in the three medical insurance schemes i.e. UEBMI, URBMI and NCMS, and to measure the inequity of the utilization due to household income in the different medical insurance schemes in a city of Sichuan province in southwest China. Our study provides possible explanations for the disparity in utilization of medical services among the elderly and provides some suggestions for formulating policy that could eliminate such inequity.

\section{Methods}

\section{Participants and sampling}

The study used a multiple-stage cluster sampling method to randomly select the participant sample. The entire county was clustered by the government administrative geographic system (i.e., town and village). A total of 24 towns and 96 villages were randomly selected. In each community or village, about 100 households were randomly selected, resulting in 10,000 households. All family members were invited to the survey. Of the participants investigated, 9793 individuals aged 60 years and above were our study population.

\section{Measures}

We collected data through face-to-face interviews by a three-part questionnaire. The first part covered social- demographic characteristics including gender, age, education, insurance, household income; the second part was the need for medical services including presence of physician-diagnosed chronic diseases and two-week health situation; the third part was the state of medical services utilization including physician visit within the last 2 weeks and hospitalization within the last 1 year.

The dependent variables in our study were the utilization of outpatient services in the last 2 weeks and hospitalization services within the last 1 year. The survey asked, "During the past 2 weeks, have you been sick?" Those who had illness were further asked, "Have you see a doctor for treatment?" We grouped respondents who visited the doctor as outpatient service users. The remaining individuals were classified as non-outpatient service users. Hospitalization in the last year was determined by the survey question, "Have you been hospitalized in the past year?" From this question, we categorized respondents into hospital users and nonhospital users.

\section{Statistical analysis}

First, we used the Chi-square test to compare demographic characteristics among the elderly enrolled in different medical insurance categories. Second, binary logistic regression models were used to study the disparity in utilization of outpatient services and hospitalization services among the three cohorts; the average household income was the important independent variable we focused on.

Before the binary logistic regressions, we divided each of the categories into five levels based on the average household income (Table 2). We did not subdivide these categories according to a unified standard because there was an obvious difference between the three kinds of participants in terms of income, and the main aim of the study was to explore the internal inequities of the three categories in the insurance system.

For outpatient, the dependent variable was the utilization of medical services in the last two weeks if the person had illness, and the independent variables included gender, age, education, the status of chronic diseases and the average household income.

For hospitalization, the dependent variable was the utilization of hospitalization services, and the independent

Table 2 The delamination standard of income among the three categories (Yuan)

\begin{tabular}{llll}
\hline Income grade & UEBMI & URBMI & NCMS \\
\hline I & $\leq 2500$ & $\leq 1200$ & $\leq 350$ \\
II & $2501-3520$ & $1201-2000$ & $351-800$ \\
III & $3521-4500$ & $2001-2800$ & $801-1370$ \\
IV & $4501-5600$ & $2801-4000$ & $1371-2500$ \\
V & $>5600$ & $>4000$ & $>2500$ \\
\hline
\end{tabular}


variables were the same as the outpatient services except that the two-week health situation was added.

All the variables used in these binary logistic regressions are summarized in Table 3.

Finally, we applied the concentration index (CI) to measure the equity in utilization of medical services among the three cohorts.

The concentration curve provides a means of assessing the degree of income-related inequity in the distribution of a health variable [27], which plots the cumulative percentage of the population, ranked by economic state ( $\mathrm{x}$ axis), against the cumulative percentage of the health variable (y-axis). If everybody has the same value of the health variable regardless of economic state, the concentration curve will coincide with the 45-degree line which is called the line of equity. If the concentration curve lies above (below) the line of equity, it means that poorer people have higher (lower) values of the health variable.

The $\mathrm{CI}$ is defined as twice the area between the concentration curve and the line of equity. The index is negative when the curve lies above the line of equity. On the other hand, the index takes a positive value when the curve lies below the line of equity. The index can be calculated by the following equation:

$$
\mathrm{C}=2 / \mu \operatorname{cov}\left(\mathrm{h}_{\mathrm{i}}, \mathrm{r}_{\mathrm{i}}\right)
$$

where $h_{i}$ is the health status of the ith individual, $r_{i}$ is the fractional rank of the ith individual in terms of economy and $\mu$ is the mean of the health status.

The CI value ranges from -1 to 1 , and the value represents the level of the equity. A positive (negative) index suggests the health variable concentrated among the rich (poor). The result indicates greater equitability when the value approaches 0 [28].

In this study, we calculated the $\mathrm{CI}$ of the utilization rate to explain the underlying equity. However, the utilization rate can be influenced by various factors, so before the calculation, we standardized the rate to keep the other factors, except for the economy, at the same level to ensure that the rate was influenced by the economy only. Our specific methods are outlined below:

First, we built the equation based on the binary logistic regression models:

$$
\ln (\mathrm{P} / 1-\mathrm{P})=\alpha_{0}+\sum \beta_{\mathrm{i}} \mathrm{x}_{\mathrm{i}}+\beta_{\mathrm{j}} \mathrm{x}_{\mathrm{j}}
$$

In the equation, $\mathrm{P}$ represents the rate; $\mathrm{x}_{\mathrm{i}}$ represents the other factors influencing the rate, such as gender, age and so on; and $x_{j}$ represents the economy. We substituted $x_{i}$ with the mean value to minimize their effects and maximize the influence of economy.

Finally, we substituted standardized rates into this formula (1) to get the corrected CI.

All data management and statistical analyses were performed with SPSS 21.0 (descriptive analyses and binary logistic regressions) and SAS 9.4 (concentration index).

\section{Results \\ Descriptive analysis}

A total of 9793 adult participants over age 60 participated. Of these, 9600 participants (1385 in UEBMI, 687 in URBMI, and 7528 in the NCMS), or $98.03 \%$, were insured by the basic social medical insurance. Table 4 presents the descriptive statistics of variables used in this study for those who were insured through the basic social medical insurance system. As shown in the table, there were demographic differences (gender, age, education, household income) between the participants in the three categories. Additionally, the average household monthly income was degressive in the sequence of UEBMI, URBMI, and the NCMS, and individuals who were enrolled in UEBMI demonstrated greater medical needs.

\begin{tabular}{|c|c|c|}
\hline Variables & Type of variable & Measurement \\
\hline \multicolumn{3}{|l|}{ Dependent variables } \\
\hline utilization of outpatient services & Categorical & $\mathrm{No}=0 ; \mathrm{Yes}=1$ \\
\hline utilization of hospitalization services & Categorical & $\mathrm{No}=0 ; \mathrm{Yes}=1$ \\
\hline \multicolumn{3}{|l|}{ Independent variables } \\
\hline gender & Categorical & Male $=1 ;$ Female $=2$ \\
\hline age & Categorical & $60 \sim 74=1 ; 75 \sim=2$ \\
\hline education & Categorical & No formal education $=1$; Primary school $=2$; Junior high school or higher $=3$ \\
\hline chronic diseases & Categorical & $\mathrm{No}=0 ; \mathrm{Yes}=1$ \\
\hline two-week prevalence ${ }^{a}$ & Categorical & $\mathrm{No}=0 ; \mathrm{Yes}=1$ \\
\hline household income & Categorical & $\begin{array}{l}\text { Grade I }=1 ; \text { Grade } \|=2 ; \\
\text { Grade } I I=3 ; \text { Grade IV }=4 ; \text { Grade } V=5\end{array}$ \\
\hline
\end{tabular}

Table 3 Summary of the variables in these binary logistic regressions 
Table 4 Summary statistics among the three cohorts enrolled in different medical insurance systems

\begin{tabular}{|c|c|c|c|c|c|}
\hline Variables & $\begin{array}{l}\text { UEBMI } \\
(N=1385)\end{array}$ & $\begin{array}{l}\text { URBMI } \\
(N=687)\end{array}$ & $\begin{array}{l}\text { NCMS } \\
(N=7528)\end{array}$ & $x^{2} / F$ & $P$ \\
\hline Gender & & & & 57.177 & $<0.001$ \\
\hline male & 773(55.8\%) & $263(38.3 \%)$ & $3685(49.0 \%)$ & & \\
\hline female & $612(44.2 \%)$ & $424(61.7 \%)$ & $3843(51.0 \%)$ & & \\
\hline Age, year & & & & 11.255 & 0.004 \\
\hline $60 \sim 74$ & 1008(72.8\%) & $539(78.5 \%)$ & $5761(76.5 \%)$ & & \\
\hline $75 \sim$ & $377(27.2 \%)$ & $148(21.5 \%)$ & $1767(23.5 \%)$ & & \\
\hline Education & & & & 1715.927 & $<0.001$ \\
\hline no formal education & $98(7.1 \%)$ & $186(27.1 \%)$ & $2738(36.4 \%)$ & & \\
\hline Primary school & $478(34.5 \%)$ & $344(50.1 \%)$ & $3902(51.8 \%)$ & & \\
\hline Junior high school or higher & $809(58.4 \%)$ & $157(22.8 \%)$ & $888(11.8 \%)$ & & \\
\hline Having chronic diseases & $914(66.0 \%)$ & $417(60.7 \%)$ & $4602(61.2 \%)$ & 11.980 & 0.003 \\
\hline Two-week prevalence ${ }^{a}$ & $717(51.8 \%)$ & $309(45.0 \%)$ & $3166(42.1 \%)$ & 45.378 & $<0.001$ \\
\hline Average household income (Yuan)/month & 4202.68 & 2927.31 & 1556.15 & 1363.467 & $<0.001$ \\
\hline
\end{tabular}

${ }^{a}$ The two-week prevalence was the prevalence before the study within two weeks

The indicators of the utilization of medical services are presented in Table 5 . A total of $78.5 \%$ of individuals said they see a doctor when they feel physically ill, and there was no significant difference among the three different insurance systems. However, it was clear that those enrolled in the NCMS had lower hospitalization rates. In regard to medical expenses, compared with UEBMI and URBMI, the expense of participants enrolled in the NCMS was lower. However, in reality, those enrolled in the NCMS generally incurred more cost than their UEBMI counterparts when they utilized the hospitalization medical services, due to their lower rate of reimbursement.

\section{Binary logistic regressions analysis}

We performed binary logistic regressions for the utilization of outpatient and hospitalization services to investigate the influence of income on utilization. Table 6 shows the results of income in outpatient services. In regards to utilization of outpatient services, as the table shows, there was no statistical disparity among the different income levels in UEBMI and URBMI. However, in the NCMS, there was a significant indication that those with higher incomes tended toward higher utilization.
From Table 7, we can see that people with higher incomes showed a greater likelihood of utilizing hospitalization services than poorer people, regardless of the insurance system. In addition, we found that the odds ratio of UEBMI tended to be larger as the income increased, while this value was relatively stable in the NCMS.

\section{Equity analysis}

Table 8 provides the results of using CI to measure the inequity of medical services utilization among the different kinds of medical insurance. First, the results indicated that all the $\mathrm{CI}$ values were positive and that the $\mathrm{CI}$ for hospitalization was larger than that for outpatient services. Moreover, the CI of the NCMS was larger than those of the two other medical insurance systems in terms of outpatient services, while the CI of hospitalization yielded precisely the opposite result.

\section{Discussion}

The present study showed that the coverage of medical insurance was $98.0 \%$, which indicates that China has achieved much in the establishment of basic social medical insurance. However, there are still some people who

Table 5 The indicators of the utilization of medical services among the three categories

\begin{tabular}{|c|c|c|c|c|c|c|}
\hline Variables & UEBMI & URBMI & NCMS & Average & $x^{2} / F$ & P \\
\hline Two-week visiting rate among ill people (\%) & 78.5 & 77.7 & 78.6 & 78.5 & 0.160 & 0.923 \\
\hline Per outpatient expense (Yuan) & 469.71 & 328.09 & 290.01 & 323.90 & 5.985 & 0.003 \\
\hline Hospitalization rate (\%) & 24.2 & 24.9 & 17.7 & 19.2 & 46.817 & $<0.001$ \\
\hline Per inpatient expense (Yuan) & 9486.19 & 9220.78 & 5958.10 & 6902.62 & 18.047 & $<0.001$ \\
\hline Inpatient expenses by self (Yuan) & 2995.28 & 3825.72 & 3464.61 & 3412.10 & 0.823 & 0.439 \\
\hline Rate of reimbursement (\%) & 68.42 & 58.51 & 41.85 & 49.43 & 14.174 & 0.001 \\
\hline
\end{tabular}


Table 6 Binary logistic regression analyses for utilization of outpatient services

\begin{tabular}{|c|c|c|c|c|}
\hline System & Income grade & B & $P$ & $\mathrm{OR}^{\mathrm{a}}(95 \% \mathrm{Cl})$ \\
\hline \multirow[t]{5}{*}{ UEBMI } & I & & & 1.000 \\
\hline & || vs I & -0.018 & 0.950 & $0.982(0.559 \sim 1.725)$ \\
\hline & III vs I & 0.423 & 0.159 & $1.526(0.847 \sim 2.748)$ \\
\hline & IV vs I & 0.283 & 0.349 & $1.327(0.735 \sim 2.395)$ \\
\hline & V vs I & 0.289 & 0.340 & $1.336(0.738 \sim 2.418)$ \\
\hline \multirow[t]{5}{*}{ URBMI } & I & & & 1.000 \\
\hline & || vs I & 0.155 & 0.712 & $1.167(0.514 \sim 2.653)$ \\
\hline & |II vs I & 0.024 & 0.956 & $1.024(0.433 \sim 2.421)$ \\
\hline & IV vs I & 0.229 & 0.577 & $1.257(0.562 \sim 2.813)$ \\
\hline & V vs I & 0.377 & 0.449 & $1.458(0.549 \sim 3.874)$ \\
\hline \multirow[t]{5}{*}{ NCMS } & I & & & 1.000 \\
\hline & || vs I & 0.080 & 0.536 & $1.083(0.842 \sim 1.393)$ \\
\hline & |II vs I & 0.145 & 0.297 & $1.156(0.881 \sim 1.517)$ \\
\hline & IV vs I & 0.287 & 0.035 & $1.332(1.020 \sim 1.741)$ \\
\hline & V vs I & 0.352 & 0.018 & $1.422(1.063 \sim 1.902)$ \\
\hline
\end{tabular}

aR: Odds Ratio

remain uninsured among a large population base, which indicates a worthy goal to strive for.

In our investigation, there was no fundamental difference among the elderly under the three kinds of medical insurance in the utilization of outpatient services if they were ill. The treatment rates were approximately $78 \%$, it could be because the expense was affordable for the elderly. Additionally, we found that members of the NCMS

Table 7 Binary logistic regression analyses for utilization of hospitalization services

\begin{tabular}{|c|c|c|c|c|}
\hline System & Income grade & B & $P$ & $\mathrm{OR}^{\mathrm{a}}(95 \% \mathrm{Cl})$ \\
\hline \multirow[t]{5}{*}{ UEBMI } & I & & & 1.000 \\
\hline & || vs I & 0.443 & 0.011 & $1.557(1.105 \sim 2.195)$ \\
\hline & III vs I & 0.424 & 0.018 & $1.529(1.075 \sim 2.174)$ \\
\hline & IV vs I & 0.586 & 0.001 & $1.796(1.283 \sim 2.514)$ \\
\hline & V vs I & 0.613 & 0.001 & $1.846(1.292 \sim 2.636)$ \\
\hline \multirow[t]{5}{*}{ URBMI } & I & & & 1.000 \\
\hline & || vs I & 0.634 & 0.043 & $1.885(1.021 \sim 3.480)$ \\
\hline & |II vs I & 0.646 & 0.050 & $1.907(1.001 \sim 3.635)$ \\
\hline & IV vs I & 0.796 & 0.008 & $2.216(1.233 \sim 3.981)$ \\
\hline & V vs I & 0.468 & 0.179 & $1.597(0.807 \sim 3.163)$ \\
\hline \multirow[t]{5}{*}{ NCMS } & । & & & 1.000 \\
\hline & || vs I & 0.194 & 0.046 & $1.215(1.003 \sim 1.470)$ \\
\hline & ||| vs I & 0.235 & 0.022 & $1.265(1.035 \sim 1.547)$ \\
\hline & IV vs I & 0.194 & 0.048 & $1.215(1.002 \sim 1.473)$ \\
\hline & V vs I & 0.245 & 0.018 & $1.278(1.042 \sim 1.566)$ \\
\hline
\end{tabular}

${ }^{\mathrm{a} O R: \text { Odds Ratio }}$ had lower outpatient costs than members of the two other systems. The reason may be that the members of NCMS prefer to seek medical services in primary health care institutions where the expense is lower [10, 29]. When comparing the equity of the three medical insurances, we found that there was no significant difference in the utilization of outpatient service between different income levels in UEBMI and URBMI. However, in the NCMS, there was a tendency for the higher income group to utilize more services. This indicates that the equity of UEBMI and URBMI is better than NCMS. As we know, the NCMS are mainly targeted at hospitalization and the critical diseases of outpatient, and the benefit packages for medical services are not as munificent as those of UEBMI, and the enrolled have to pay for most outpatient fees personally [11, 30]. Although the expense of outpatient service was relative lower, but there were still some low-income population in NCMS who couldn't easily afford it [31].

As far as hospitalization is concerned, the results indicated that the higher income group utilized hospitalization more, regardless of the insurance system. Thus, it can be speculated that inequity is widespread in the utilization of hospitalization. Additionally, we found that the range of hospitalization standardized rate among different income levels in the NCMS was between $13.30 \%$ and $16.38 \%$, and the disparity was about $3 \%$, which was significantly smaller than URBMI and UEBM (about 10\%). Interestingly, this indicated that the NCMS was more equitable than URBMI and UEBMI in terms of hospitalization. This was verified by comparing the value of CI. And the CI of NCMS was smallest among the three systems. However it should be noted that the equity in NCMS was based on the overall low utilization of hospitalization regardless of income levels. This also suggested that the economic burden of hospitalization was considerable for NCMS cohort [31]. As mentioned in Table 5, the reimbursement ratio of the NCMS was lower than for the other two systems. Furthermore, we found that the hospitalization expenses of individuals in the NCMS were higher than those of participants with UEBMI, although the actual cost of the NCMS was lower.

The CI results clarify this inequity further. All the CI values we calculated were positive, which means that the richer participants had more utilization than poorer participants, whatever the medical system and the medical services. In addition, the CIs of hospitalization were larger than those of outpatient services. This result indicates that the inequity in hospitalization is more serious than for outpatient services, and the main reason is that the expenses of hospitalization are higher and thus income is crucial in deciding utilization. 
Table 8 The concentration index results among the three cohorts

\begin{tabular}{|c|c|c|c|c|c|c|}
\hline \multirow{2}{*}{$\begin{array}{l}\text { Income } \\
\text { grade }\end{array}$} & \multicolumn{3}{|c|}{ Treatment standardized rate (\%) } & \multicolumn{3}{|c|}{ Hospitalization standardized rate (\%) } \\
\hline & UEBMI & URBMI & NCMS & UEBMI & URBMI & NCMS \\
\hline । & 74.04 & 70.19 & 71.91 & 14.72 & 13.52 & 13.30 \\
\hline$\|$ & 73.69 & 73.33 & 73.50 & 21.19 & 22.76 & 15.70 \\
\hline III & 81.32 & 70.69 & 74.75 & 20.87 & 22.97 & 16.25 \\
\hline IV & 79.10 & 74.75 & 77.33 & 23.67 & 25.73 & 15.70 \\
\hline V & 79.20 & 77.44 & 78.45 & 24.16 & 19.98 & 16.38 \\
\hline $\mathrm{Cl}$ & 0.0162 & 0.0173 & 0.0179 & 0.0817 & 0.0605 & 0.0319 \\
\hline
\end{tabular}

\section{Conclusion}

We found that inequities still exist in all three health insurance systems, in particular, the inequities in utilization of hospitalization were more severe than outpatient services. When comparing the equity of the three medical insurances, UEBMI and URBMI were better than NCMS in the equity of outpatient services. NCMS was more equitable than URBMI and UEBMI in terms of hospitalization. However, the equity of hospitalization in NCMS was based on the "overall low utilization of hospitalization regardless of income levels". Thus, basic social medical insurance can be further improved to make sure vulnerable groups utilize the medical services better. A comprehensive approach to reduce the inequity of the three basic social medical insurances should focus on the following factors: 1) Covering more basic outpatient services in the medical insurances, especially for NCMS; 2) raising the reimbursement rate of hospitalization for the three basic social medical insurance systems, especially for NCMS; 3) Eliminate the disparities of the three basic social medical insurance systems under the different health insurance plans. 4) For low-income residents, specific insurance policies including reducing deductible, covering more medical service and increasing reimbursement ratio could be considered.

\section{Abbreviations}

Cl: concentration index; NCMS: New Cooperative Medical Scheme; UEBMI: Urban Employee Basic Medical Insurance; URBMI: Urban Resident Basic Medical Insurance

\section{Funding}

This study was supported by National Natural Science Foundation of China (grant no. 71473171).

\section{Availability of data and materials}

The datasets used and/or analyzed during the current study are available from the corresponding author on reasonable request.

\section{Authors' contributions}

Design of study: LX, LNX. Analyses: CR. Drafting manuscript: CR, LX. Critical revisions: All authors. Final approval: All authors.

\section{Ethics approval and consent to participate}

All procedures performed in studies involving human participants were in accordance with the ethical standards of the institutional and national research committee and with the 1964 Helsinki Declaration and its later amendments or comparable ethical standards. The study protocol was approved by the Sichuan University, Chengdu, China. Informed consent was obtained from all individual participants included in the study.

\section{Competing interests}

The authors declare that they have no competing interests.

\section{Publisher's Note}

Springer Nature remains neutral with regard to jurisdictional claims in published maps and institutional affiliations.

Received: 18 December 2017 Accepted: 13 April 2018

Published online: 02 May 2018

References

1. Cooper RN, Chow GC. China's economic transformation. Foreign Affairs. 2017:82:161

2. S T QM, L C HB, T E MW. Tackling the challenges to health equity in China. Lancet (London, England). 2008;372:1493.

3. Anand S, Fan VY, Zhang J, Zhang L, Ke Y, Dong Z, Chen LC. China's human resources for health: quantity, quality, and distribution. Lancet. 2008:372:1774-81

4. Braveman P, Gruskin S. Defining equity in health. J Epidemiol Community Health. 2003;57:254

5. Whitehead M. The concepts and principles of equity and health. Int J Health Serv Plann Adm Eval. 1992;22:429-45.

6. Gerdtham UG. Equity in health care utilization: further tests based on hurdle models and Swedish micro data. Sse/efi Working Paper. 1997:6:303-19.

7. Lemstra M, Mackenbach J, Neudorf C, Nannapaneni U. High health care utilization and costs associated with lower socio-economic status: results from a linked dataset. Can J Public Health. 2009;100:180-3.

8. Penning MJ, Zheng C. Income inequities in health care utilization among adults aged 50 and older. Can J Aging. 2016;35:55.

9. Chen Z, Lu M. Globalization and regional income inequality in China. Berlin Heidelberg: Springer; 2016

10. Fang $H$, Meng Q, Rizzo JA: Do different health insurance plans in China create disparities in health care utilization and expenditures? 2014.

11. Dong K. Medical insurance system evolution in China. China Econ Rev. 2009;20:591-7.

12. Hsiao WC, Maynard A. Health economics in China. Foreword. Health Econ. 2009:18(Suppl 2):S1-2

13. Meng Q, Fang H, Liu X, Yuan B, Xu J. Consolidating the social health insurance schemes in China: towards an equitable and efficient health system. Lancet. 2015;386:1484-92.

14. Yang XW. Comparison of health services need and utilization of people under different social medical insurance. Chin Health Serv Manage. 2012; (In Chinese)

15. Gao JM, Chen X, Pei YL, Yan JE: Comparative analysis on the residents' health service need and utilization under three basic medical insurance system. Chin J Health Policy 2011. (In Chinese).

16. Yip W, Hsiao WC. The Chinese health system at a crossroads. Health Aff. 2008;27:460.

17. Lin W, Liu GG, Chen G. The urban resident basic medical insurance: a landmark reform towards universal coverage in China. Health Econ. 2009;18:S83-96. 
18. Ministry of Health. China health statistical yearbook 2012. Beijing: China Union Medical University Press; 2012. (In Chinese)

19. Ngan RMH: Global ageing, social development, and the well-being of the World's elders. New York: Palgrave Macmillan US; 2017.

20. Moody HR: Abundance of life: human development policies for an aging society. New York: Columbia University Press 1988.

21. Anderson LA, Prohaska TR. Fostering engagement and independence: opportunities and challenges for an aging society. Health Educ Behav. 2014:41:5S-9S.

22. Hu J, Huang CC. Health Service Utilization and Expenditure of the Elderly in China. Asian Soc Work Policy Rev. 2016;10:162-74.

23. Moore TJ, Mattison DR. Adult utilization of psychiatric drugs and differences by sex, age, and race. JAMA Intern Med. 2017;177:274-5.

24. Yoo KH. Medical utilization and cost in patients with overlap syndrome of chronic obstructive pulmonary disease and asthma. COPD. 2014;11:163.

25. Ruo-Yan LU, Gao JM, Yong-Jian XU. Status and decomposition of health equity among the elderly in Fujian province. Chin J Public Health. 2016; (In Chinese)

26. Health and Family Planning Commission of Sichuan province. Health statistics yearbook of Sichuan(2016). Chengdu: Southwest jiaotong university press; 2017. (In Chinese)

27. World Bank: Quantitative Techniques for Health Equity Analysis. Technical Note 2003, No.6. In: http://siteresources.worldbank.org/INTPAH/Resources/Publications/ Quantitative-Techniques/health_eq_tn06.pdf. Accessed 18 Apr 2018.

28. O'Donnell O, Doorslaer EV, Wagstaff A, Lindelow M. Analyzing health equity using household survey data: a guide to techniques and their implementation. World Bank. 2008;86:816.

29. O'Connor GE. The impact of insurance coverage on consumer utilization of health services. Int J Bank Mark. 2015;33:276-97.

30. Teng H, Cao Z, Liu J, Liu P, Hua W, Yang Y, Xiong L. Health status and burden of health care costs among urban elderly in China. Asia Pac J Public Health. 2015;27:61S.

31. Li X, Zhang W. The impacts of health insurance on health care utilization among the older people in China. Soc Sci Med. 2013;85:59-65.

\section{Ready to submit your research? Choose BMC and benefit from:}

- fast, convenient online submission

- thorough peer review by experienced researchers in your field

- rapid publication on acceptance

- support for research data, including large and complex data types

- gold Open Access which fosters wider collaboration and increased citations

- maximum visibility for your research: over $100 \mathrm{M}$ website views per year 